\title{
Structural Collapse Analysis of Framed Structures under Impact Loads Using ASI-Gauss Finite Element Method Kyaw Myo Lynn ${ }^{1 *}$ and Daigoro ISOBE ${ }^{2}$
}

\author{
${ }^{1 *}$ Graduate School, University of Tsukuba, 1-1-1 Tennodai, Tsukuba-shi, Ibaraki 305-8573, Japan \\ (kyaw@kz.tsukuba.ac.jp) \\ ${ }^{2}$ Institute of Engineering Mechanics and Systems, University of Tsukuba, 1-1-1 Tennodai, Tsukuba-shi, Ibaraki \\ 305-8573, Japan (isobe@kz.tsukuba.ac.jp)
}

\begin{abstract}
The main objective of this study is to devise a technique, which, when implemented into finite element codes, is efficiently applicable to impact collapse analyses of framed structures. In this study, the formerly developed Adaptively Shifted Integration (ASI) technique for the linear Timoshenko beam element is modified into the ASI-Gauss technique by placing the numerical integration points of the two consecutive elements forming an elastically deformed member in such a way that stresses and strains are evaluated at the Gaussian integration points of the two-element member. On comparison with the ASI technique, the ASI-Gauss technique proves its higher accuracy and efficiency in elastic range. Instead of applying impact loads in the form of nodal forces, this study simulates the impact phenomenon by means of contacts between the elements involved and the elemental contact algorithm is verified from the point of conservation of energy. Impact analyses considering member fracture with different sets of parameters are performed using a high-rise framed structure and a small aircraft. From the results obtained, we can observe propagation phenomena of impact loads and shock waves. Different parameters of the aircraft produce proper difference in impact damage. Results also indicate that the influence of mass of the aircraft has a stronger influence on impact damage than its velocity. Moreover, soon after impact, tensile stresses are observed in the columns that were compressed by dead loads before impact.
\end{abstract}

Keywords: ASI-Gauss technique; ASI technique; Impact; Elemental contact; Member fracture; Finite element method

\section{Introduction}

The progressive collapse of World Trade Center towers in New York, USA revealed the structural vulnerability of tall steel buildings to the impact of a fast moving object. Technical investigations are necessary to clarify the technical conditions that contributed to the progressive collapse and to improve the ways buildings are designed, constructed, maintained and used. And numerical simulation is considered to be one of the means to investigate such problems.

Advancements in computing technology have helped the development of various numerical analysis methods and some of them have been applied to analyze dynamic behaviors with strong nonlinearities and discontinuities. The Distinct Element Method (DEM) [1] follows the discontinuum approach, that is, the analytical model is formed by a number of distinct interacting general-shaped elements to simulate the perfectly discrete behavior. The Discontinuous Deformation Analysis (DDA) [2] models a discontinuous material as a system of individually deformable blocks that move independently without interpenetration. DDA is known to be able to cope with large deformations and strong discontinuities. The Applied Element Method (AEM), which can predict crack initiation and propagation in the material [3] and can also follow the total behavior from zero loading to complete collapse, has also been developed and applied to detailed nonlinear analysis of reinforced concrete structures. However, the above-mentioned discrete numerical methods are computationally intensive and need detailed modeling. Therefore, they are 
suitable only for detailed analyses of either two-dimensional or small three-dimensional models.

On the other hand, the Finite Element Method (FEM), which is based on continuum material equations, has been successfully applied to a wide range of engineering problems including structural analyses of large-scale structures. However, FEM is generally limited to analyses of relatively small displacements and it needs complicated modifications to apply to nonlinear and discontinuous problems. The main objective of this study is to devise a technique, which, when implemented into finite element codes, can simulate dynamic behaviors with strong nonlinearities and discontinuities and is efficiently applicable to impact collapse analyses of framed structures.

Toi and Isobe developed the Adaptively Shifted Integration (ASI) technique [4][5][6] for the linear Timoshenko beam element, which can be easily implemented into the existing finite element codes. In this technique, the numerical integration point is shifted immediately after the occurrence of a fully plastic section in the element so that a plastic hinge is formed exactly at that section. As a result, the ASI technique gives a more precise solution than the conventional finite element method, and has become able to simulate dynamic behaviors with strong nonlinearities by a small number of elements. However, when the number of elements per member is very small, it still lacks accuracy in the elastic range compared to the converged solution. If the model to be analyzed is a large structure, it is desirable, from the point of calculation costs, to use a small number of elements per member. So it is very important to have a numerical scheme that ensures accuracy even when the number of elements per member is small. In this study, the ASI technique is modified into the ASI-Gauss technique by placing the numerical integration points of the two consecutive elements forming an elastically deformed member in such a way that stresses and strains are evaluated at the Gaussian integration points of the two-element member. And the accuracy of the ASI-Gauss technique is verified by comparing with the ASI technique and the conventional FEM.

Generally, it is difficult to determine the loads resulted in the structures due to an impact. And applying impact loads to an analytical model in the form of nodal forces may not well simulate the impact phenomenon. This study tries to simulate the impact phenomenon by means of contacts between the elements involved. The elemental contact algorithm [7][8] is verified from the point of conservation of energy. Furthermore, dynamic collapse analyses considering member fracture are performed to simulate the impact of a small aircraft into a ten-storied steel framed structure, and observations are made to evaluate the influence of mass, velocity and size of the aircraft on the impact damage.

\section{Methods}

Incremental finite element formulation for linear Timoshenko beam element, which is used throughout this study, is summarized in this section. Then, the existing ASI technique, the newly proposed ASI-Gauss technique and algorithms considering member fracture and elemental contact are explained.

\subsection{Adaptively Shifted Integration (ASI) technique}

Elasto-plastic analyses of framed structures using the linear Timoshenko beam element are based on the following incremental form of the principle of virtual work:

$$
\delta \mathrm{V}-\delta \mathrm{W}=\int_{-L / 2}^{L / 2}\{\delta \Delta \varepsilon\}^{T}\{\Delta \sigma\} d z-\{\delta \Delta u\}^{T}\{\Delta f\}=0
$$

In Eq.(1), $\delta \mathrm{V}$ and $\delta \mathrm{W}$ are the internal work and the external work respectively. $\{\Delta \varepsilon\},\{\Delta \sigma\}$, $\{\Delta \mathrm{u}\}$, and $\{\Delta \mathrm{f}\}$ are the generalized strain increment vector, the generalized stress (resultant force) increment vector, the nodal displacement increment vector and the external force increment vector, respectively. The symbols $\delta$ and $\Delta$ denote variation and increment. The Local coordinates, nodal numbers and displacement components $\left(\mathrm{u}, \mathrm{v}, \mathrm{w}, \theta_{\mathrm{x}}, \theta_{\mathrm{y}}, \theta_{\mathrm{z}}\right)$ are shown in Fig.1.

The relation between the generalized strain increment and nodal displacement increment vectors are given by the following equation:

$$
\{\Delta \varepsilon(r)\}=[B(s)]\{\Delta u\}
$$

Here, $[\mathrm{B}(\mathrm{s})]$ is the generalized strain-nodal displacement matrix. $\mathbf{s}$ is the location of the numerical 


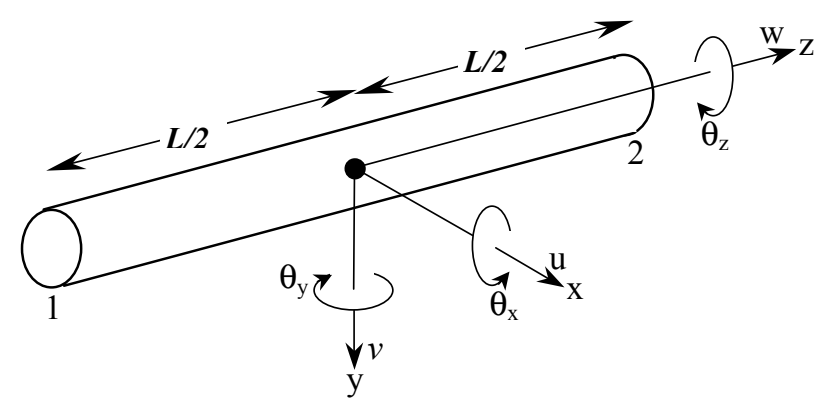

Fig.1. Definitions of local coordinates and displacements

integration point and $\mathbf{r}$ the location where stresses and strains are actually evaluated. We refer $\mathbf{r}$ as the stress evaluation point later in this paper. $\mathbf{s}$ is a non-dimensional quantity, which is defined as $\mathrm{z} /(\mathrm{L} / 2)$ where $\mathrm{L}$ is the length of the element. s takes a value between -1 and 1 . It should be noted here that the linear Timoshenko beam element uses one-point integration to avoid shear locking.

When the element behaves elastically, the relation between resultant force increment vector and generalized strain increment vector is given by the following equation:

$$
\{\Delta \sigma(r)\}=\left[D_{e}(r)\right]\{\Delta \varepsilon(r)\}
$$

Here, $\left[D_{e}\right]$ is the stress-strain matrix for elastic deformation. $\left[D_{e}\right]$ will change to $\left[D_{p}\right]$, when plastic deformation is determined by the plastic flow theory using the following form of yield function:

$$
f_{y}(\sigma(r))-1=0
$$

Substitution of Eqs.(2) and (3) into Eq.(1) leads to the following form of elemental stiffness matrix:

$$
[K]=L[B(s)]^{T}\left[D_{e}(r)\right][B(s)]
$$

In the ASI technique, numerical integration points are shifted immediately after the formation of a fully plastic section in the element in order to form a plastic hinge exactly at that section. When a plastic hinge is judged to be unloaded, the corresponding numerical integration point is shifted back to its normal position. Here, the normal position means the location where the numerical integration point is placed when the element acts elastically.

Figure 2 shows a linear Timoshenko beam element and its physical equivalence to a rigid-body-spring-model (RBSM). As shown in Fig.2, the relationship between the locations of the numerical integration point and the stress evaluation point where a plastic hinge is actually formed is expressed as follows:

$$
\begin{aligned}
& r_{1}=-s_{1} \\
& s_{1}=-r_{1}
\end{aligned}
$$

When the entire region of an element behaves elastically, the numerical integration point is placed at the midpoint of the element $\left(\mathbf{s}_{1}=0\right)$ which gives $\mathbf{r}_{1}=0$ from Eq.(6) in this case. The elemental stiffness matrix for the element is given by the following equation:

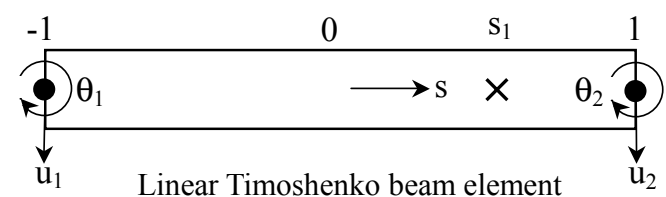

$\times$ Numerical integration point

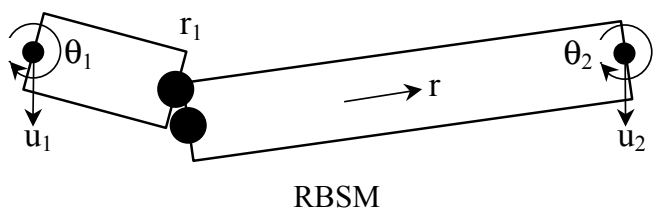

Rotational and shear spring connecting rigid bars (Plastic hinge including the effect of shear force)

Fig.2. Linear Timoshenko beam element and its physical equivalent 


$$
[K]=L[B(0)]^{T}\left[D_{e}(0)\right][B(0)]
$$

The generalized strain increment vector $\{\Delta \varepsilon(0)\}$ and the resultant force increment $\{\Delta \sigma(0)\}$ are calculated as follows:

$$
\begin{aligned}
& \{\Delta \varepsilon(0)\}=[B(0)]\{\Delta u\} \\
& \{\Delta \sigma(0)\}=\left[D_{e}(0)\right]\{\Delta \varepsilon(0)\}
\end{aligned}
$$

The resultant forces calculated from Eq.(7c) are physically those at the midpoint of the element. However, the resultant forces except for bending moments have constant values in the element. According to the elementary beam theory, the relations between the bending moments and shear forces are given as below.

$$
\begin{aligned}
& V_{x}=-\frac{d M_{y}}{d z} \\
& V_{y}=-\frac{d M_{x}}{d z}
\end{aligned}
$$

Here, $M_{x}$ and $M_{y}$ are the bending moments around $x-$ and $y$ axes while $V_{x}$ and $V_{y}$ are the shear forces along $\mathrm{x}$ - and $\mathrm{y}$ - axes. The bending moments in an elastically deformed element are determined by the following approximations:

$$
\begin{gathered}
\Delta M_{x}(s)=\Delta M_{x}(0)-\Delta V_{y}(0) \frac{L s}{2} \\
\Delta M_{y}(s)=\Delta M_{y}(0)-\Delta V_{x}(0) \frac{L s}{2}
\end{gathered}
$$

After the formation of a fully plastic section, the numerical integration point is shifted immediately to a new point $\left(\mathbf{s}_{1}=-\mathbf{r}_{1}\right)$. For instance, if a fully plastic section occurs at the right end of an element $\left(\mathbf{r}_{1}=1\right)$, the numerical integration point is shifted to the left end $\left(\mathbf{s}_{1}=-1\right)$ and vice versa. In this case, the elemental stiffness matrix, the generalized strain and resultant force increment vectors are given as follows:

$$
\begin{gathered}
{[K]=L\left[B\left(s_{1}\right)\right]^{T}\left[D_{p}\left(r_{1}\right)\right]\left[B\left(s_{1}\right)\right]} \\
\left\{\Delta \mathcal{E}\left(r_{1}\right)\right\}=\left[B\left(s_{1}\right)\right]\{\Delta u\} \\
\left\{\Delta \sigma\left(r_{1}\right)\right\}=\left[D_{p}\left(r_{1}\right)\right]\left\{\Delta \mathcal{E}\left(r_{1}\right)\right\}
\end{gathered}
$$

Here, $\left[D_{p}\right]$ is the stress-strain matrix for plastic deformation.

\subsection{ASI-Gauss technique}

In this paper, we propose the ASI-Gauss technique for elasto-plastic collapse analyses of framed structures using the linear Timoshenko beam element. As in the ASI technique, the numerical integration point is shifted immediately after the formation of a plastic hinge and it is shifted back to its normal position when the element is unloaded. The main difference between the ASI and the ASI-Gauss techniques lies in their normal positions of the numerical integration points.

The relationship between the locations of the numerical integration point and the stress evaluation point is expressed as follows:

$$
\begin{gathered}
r_{g}=-s_{g} \\
s_{g}=-r_{g}
\end{gathered}
$$

When the entire region of an element behaves elastically, the numerical integration point is located at $\left(\mathbf{s}_{\mathbf{1}}=\mathbf{s}_{\mathbf{g}}\right)$. As shown in Fig.3, the normal position of the numerical integration point in the 


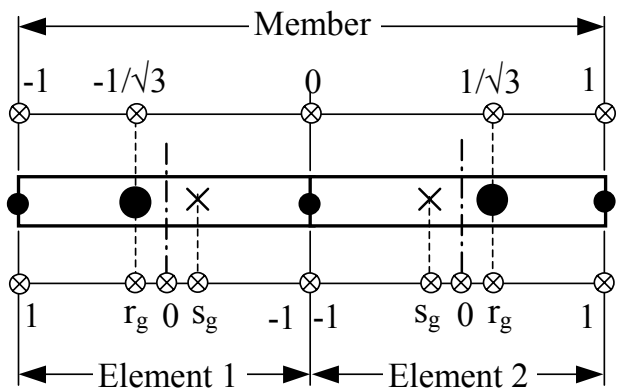

$$
\begin{aligned}
& \mathrm{s}_{\mathrm{g}}=1-(2 / \sqrt{ } 3) \\
& \mathrm{r}_{\mathrm{g}}=-1+(2 / \sqrt{ } 3) \\
& \times \text { Numerical integration point } \\
& \text { Stress evaluation point }
\end{aligned}
$$

Fig.3. Locations of numerical integration and stress evaluation points in ASI-Gauss technique

ASI-Gauss technique is $\mathbf{S}_{\mathbf{g}}=1-(2 / \sqrt{ } 3)$ and the stress evaluation point is $\mathbf{r}_{\mathbf{g}}=-\mathbf{s}_{\mathbf{g}}=-1+(2 / \sqrt{ } 3)$.

When two consecutive elements forming a member are considered as in Fig.3, the two stress evaluation points coincide with Gaussian integration points of the member. This means that stresses and strains are evaluated at Gaussian integration points when the element behaves elastically. Gaussian integration points are known to be optimal for two-point integration and the accuracy of bending deformation is mathematically guaranteed [9]. In this case, the elemental stiffness matrix, the generalized strain and resultant force increment vectors are given as follows:

$$
\begin{aligned}
& {[K]=L\left[B\left(s_{g}\right)\right]^{T}\left[D_{e}\left(r_{g}\right)\right]\left[B\left(s_{g}\right)\right]} \\
& \left\{\Delta \varepsilon\left(r_{g}\right)\right\}=\left[B\left(s_{g}\right)\right]\{\Delta u\} \\
& \left\{\Delta \sigma\left(r_{g}\right)\right\}=\left[D_{e}\left(r_{g}\right)\right]\left\{\Delta \varepsilon\left(r_{g}\right)\right\}
\end{aligned}
$$

The bending moments in an elastically deformed element are determined by the following approximations:

$$
\begin{aligned}
& \Delta M_{x}(s)=\Delta M_{x}\left(s_{g}\right)-\Delta V_{y}\left(s_{g}\right) \frac{L}{2}\left(s+s_{g}\right) \\
& \Delta M_{y}(s)=\Delta M_{y}\left(s_{g}\right)-\Delta V_{x}\left(s_{g}\right) \frac{L}{2}\left(s+s_{g}\right)
\end{aligned}
$$

Immediately after the occurrence of a fully plastic section, the numerical integration point is shifted to a new point $\left(\mathbf{s}_{1}=-\mathbf{r}_{1}\right)$ as in the ASI technique. For instance, if a fully plastic section occurs at the right end of an element $\left(\mathbf{r}_{1}=1\right)$, the numerical integration point is shifted to the left end $\left(\mathbf{s}_{1}=-1\right)$ and vice versa. The elemental stiffness matrix, the generalized strain vector and resultant force increment vector are given by Eqs.(10a), (10b) and (10c).

The yield function assumed in this study is expressed by the following equation:

$$
f_{y} \equiv\left(\frac{M_{x}}{M_{x 0}}\right)^{2}+\left(\frac{M_{y}}{M_{y 0}}\right)^{2}+\left(\frac{N}{N_{0}}\right)^{2}+\left(\frac{M_{z}}{M_{z 0}}\right)^{2}=1
$$

Here, $M_{x}, M_{y}, N$ and $M_{z}$ are the bending moments around $x-$ and $y-$ axes, the axial force and the torsional moment, respectively. Those with the subscript 0 are the values that cause a fully plastic section in an element when they act on the cross-section independently. The effect of shear forces is neglected in the yield function.

The dynamic collapse analysis is made possible by adding inertial force terms to the quasi-static computational procedure. That is, the following equation for the complete system is integrated by an appropriate time integration scheme:

$$
[M]\{\ddot{u}\}_{t+\Delta t}+[K]\{\Delta u\}=\{F\}_{t+\Delta t}-\{R\}_{t}
$$

Here, $[\mathrm{M}]$ is the total mass matrix, $[\mathrm{K}]$ the total stiffness matrix, $\{\mathrm{F}\}_{\mathrm{t}+\Delta \mathrm{t}}$ the nodal external force increment vector at $\mathrm{t}+\Delta \mathrm{t},\{\mathrm{R}\}_{\mathrm{t}}$ the nodal internal force increment vector at $\mathrm{t}$ and $\{\Delta \mathrm{u}\}$ the nodal 
displacement increment vector between $t$ and $t+\Delta t$. In this study, we use consistent mass as an elemental mass matrix which is assumed to be unaffected by the shifting of numerical integration points. Newmark's $\beta$ method is used as a numerical integration scheme for Eq.(15). And conjugate gradient $(C G)$ method is used as a solver to reduce the need of memory resources.

\subsection{Algorithm considering member fracture}

In this study, member fracture is determined by examining axial and bending strains in two elements forming a member. Member fracture is expressed by shifting the numerical integration point to the opposite end of the fractured section and by releasing the resultant forces exerting on the section simultaneously as shown in Fig.4. This causes a virtual plastic hinge to form at the fractured section. For example, if fracture occurs at the right end of the element $(\mathbf{r}=1)$, the numerical integration point is shifted to the left end $(\mathbf{s}=-1)$ and the virtual plastic hinge is formed at the right end.

Fracture is judged to occur in an element when at least one the conditions in the following equation are satisfied for the element.

$$
\left(\frac{\kappa_{x}}{\kappa_{f x}}\right)-1 \geq 0,\left(\frac{\kappa_{y}}{\kappa_{f y}}\right)-1 \geq 0,\left(\frac{\varepsilon_{z}}{\varepsilon_{f z}}\right)-1 \geq 0
$$

In the above equation, $\kappa_{\mathrm{x}}, \kappa_{\mathrm{y}}, \varepsilon_{\mathrm{z}}, \kappa_{\mathrm{fx}}, \kappa_{\mathrm{fy}}$ and $\varepsilon_{\mathrm{fz}}$ are the bending strains around $\mathrm{x}$ - and $\mathrm{y}$ - axes, the axial strain and the critical values for each strain, respectively. The values $\kappa_{\mathrm{fx}}=\kappa_{\mathrm{fy}}=0.0004$ and $\varepsilon_{\mathrm{fz}}=0.3$ are used in the analyses.

In the Finite Element Method, the mass of an element is distributed at its nodes. So, when member fracture occurs, the mass matrix $[\mathrm{M}]$ needs to be recalculated according to the new connecting conditions of the elements. Figure 5 shows the distribution of mass before and after the occurrence of fracture.

Releasing resultant forces exerting on the fractured section may cause longitudinal waves in the model. Therefore, a gradual release of resultant forces or introducing artificial viscosity is considered necessary to reduce this effect. However, an instant release technique is used in this study to preserve the simplicity of the algorithm.

It should also be noted that new virtual node points for the fractured sections are added at the

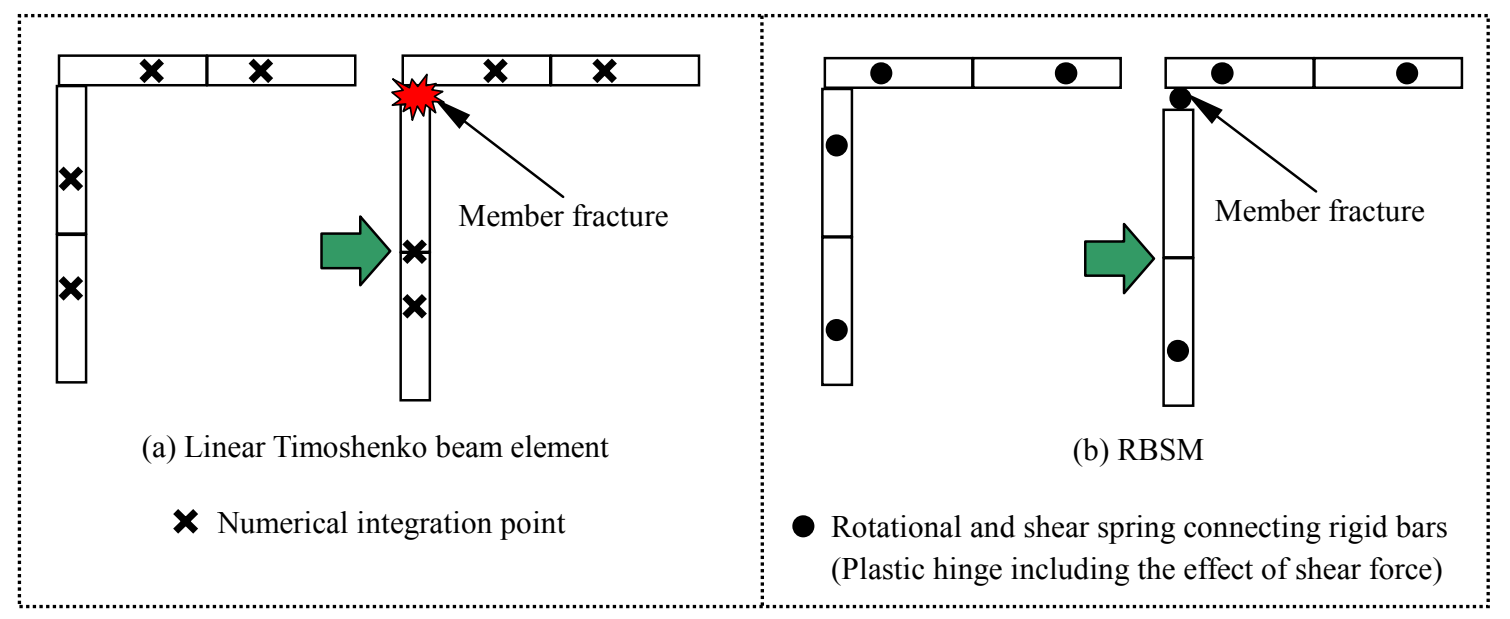

Fig.4. ASI-Gauss technique dealing with member fracture

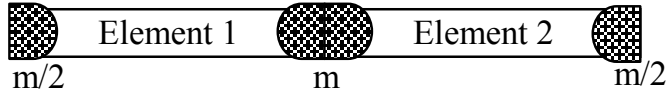

Before fracture

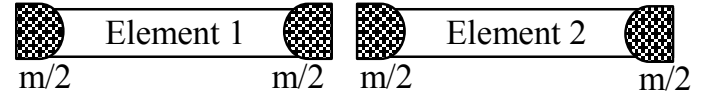

After fracture

Fig.5. Mass distribution before and after the occurrence of fracture 
post-processing stage as elements and node points are still treated as a continuous model in the calculation process. The elements with the virtual node points are then visualized as rigid bars thereafter.

\subsection{Algorithm considering elemental contact}

Generally, it is difficult to determine the loads resulted in the structures due to an impact. And applying impact loads to the model in the form of nodal forces may not well simulate the impact phenomenon. In this study, we try to simulate the impact phenomenon by means of contacts between the elements involved. Elemental contact algorithm is also useful to simulate fractured elements colliding with other elements. If this algorithm is not implemented in the analyses, unrealistic appearances such as members going through each other could take place.

Contact determination is done by examining the following two factors: (i) the distance between the approaching element and the another one, (ii) the condition under which all four nodal points lie on the same plane. Figure 6 shows the coordinates used in the contact determination.

Using the coordinates of the nodal points of the colliding element; $\mathrm{A}_{1}\left(\mathrm{x}_{\mathrm{cl}}, \mathrm{y}_{\mathrm{cl}}, \mathrm{z}_{\mathrm{cl}}\right)$, $\mathrm{A}_{2}\left(\mathrm{x}_{\mathrm{c} 2}, \mathrm{y}_{\mathrm{c} 2}, \mathrm{z}_{\mathrm{c} 2}\right)$, and another element $\mathrm{E}_{\mathrm{i}} ; \mathrm{B}_{\mathrm{i} 1}\left(\mathrm{x}_{\mathrm{i} 1}, \mathrm{y}_{\mathrm{i} 1}, \mathrm{z}_{\mathrm{i} 1}\right), \mathrm{B}_{\mathrm{i} 2}\left(\mathrm{x}_{\mathrm{i} 2}, \mathrm{y}_{\mathrm{i} 2}, \mathrm{Z}_{\mathrm{i} 2}\right)$, the condition under which all four nodal points lie on the same plane can be expressed as follows:

$$
\begin{aligned}
f(x, y, z) \equiv & \left\{\left(y_{i 1}-y_{c 2}\right)\left(z_{i 2}-z_{c 2}\right)-\left(y_{i 2}-y_{c 2}\right)\left(z_{i 1}-z_{c 2}\right)\right\}\left(x_{c 1}-x_{c 2}\right)+ \\
& \left\{\left(x_{i 2}-x_{c 2}\right)\left(z_{i 1}-z_{c 2}\right)-\left(x_{i 1}-x_{c 2}\right)\left(z_{i 2}-z_{c 2}\right)\right\}\left(y_{c 1}-y_{c 2}\right)+ \\
& \left\{\left(x_{i 1}-x_{c 2}\right)\left(y_{i 2}-y_{c 2}\right)-\left(x_{i 2}-x_{c 2}\right)\left(y_{i 1}-y_{c 2}\right)\right\}\left(z_{c 1}-z_{c 2}\right)=0
\end{aligned}
$$

When two elements lie on the same plane and exist within a specific distance from each other as calculated by the following equation, they are assumed to be in contact:

$$
\left|\overline{A_{1} B_{i 1}}\right|+\left|\overline{A_{1} B_{i 2}}\right|+\left|\overline{A_{2} B_{i 1}}\right|+\left|\overline{A_{2} B_{i 2}}\right| \leq C_{l}\left(L_{c}+L_{i}\right)
$$

Here, $\left|\overrightarrow{A_{1} B_{i 1}}\right|,\left|\overrightarrow{A_{1} B_{i 2}}\right|,\left|\overrightarrow{A_{2} B_{i 1}}\right|,\left|\overrightarrow{A_{2} B_{i 2}}\right|$ are the distances between the four nodal points and $\mathrm{L}_{\mathrm{c}}, \mathrm{L}_{\mathrm{i}}$ are

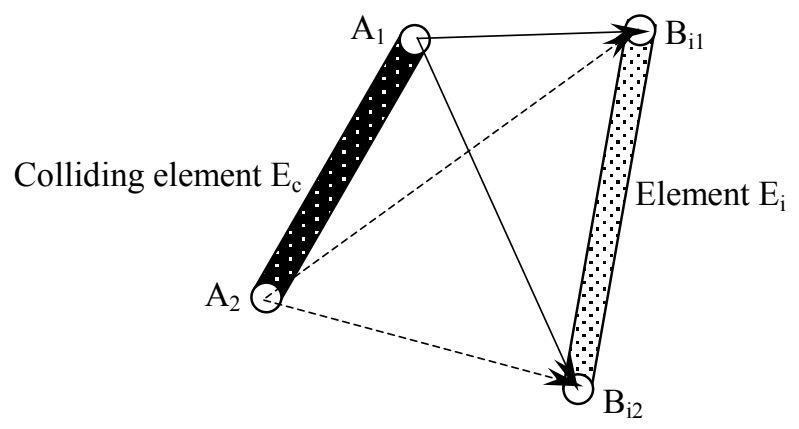

Fig.6. Coordinates used in determination of elemental contact

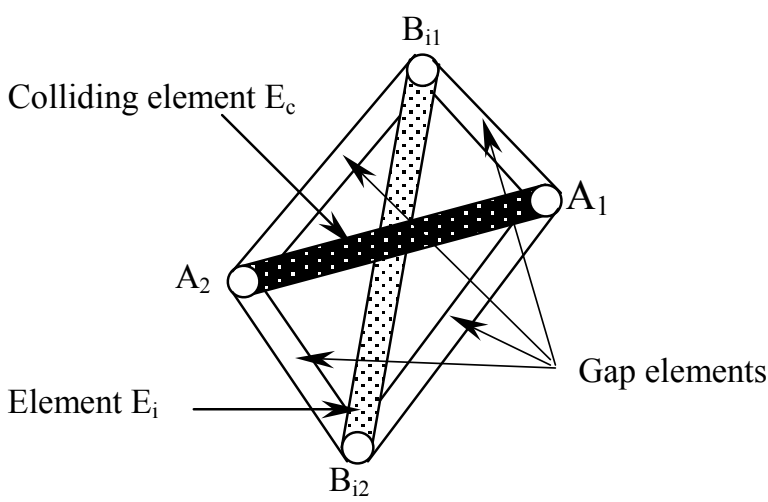

Fig.7. Four gap elements binding two elements in contact 
the lengths of colliding element $\mathrm{E}_{\mathrm{c}}$ and the element $\mathrm{E}_{\mathrm{i}}$ respectively. $C_{l}$ is the coefficient concerning contact length and a value of 1.8 is used in this study.

For the elements that do not lie on the same plane but exist within a certain distance specified by Eq.(18), another condition is given as expressed by the following equation, which assumes the elements nearly forming a plane:

$$
f(x, y, z) \leq \alpha
$$

In this study, a value of $3.0 \times 10^{-4} \mathrm{~m}^{3}$ is used for $\alpha$. Contact determination is skipped for the elements that are not approaching each other. When two elements are determined to be in contact, they are bound with a total of four gap elements as shown in Fig.7. Gap elements are assumed to have the same physical properties and the cross-section as the other elements. After certain time, the gap elements are removed from the analytical model. In this study, this binding time is set to $0.5 \mathrm{~ms}$. It is assumed that no energy loss takes place during the impact.

\section{Numerical examples}

In this section, the results of the elasto-plastic collapse analyses using a simple space frame, which is loaded both statically and dynamically, are discussed. In the analyses, we use the following three methods in order to verify the accuracy of the newly proposed ASI-Gauss technique: (a) conventional finite element method in which the numerical integration point of each element is fixed at its midpoint; (b) finite element method using the ASI technique; (c) finite element method using the ASI-Gauss technique. Moreover, the algorithm considering elemental contact is verified from the point of conservation of energy.

\subsection{Elasto-plastic collapse behaviors of framed structure under static loading}

Figure 8 shows the analyzed space frame with its dimensions, physical properties and material constants. As shown in the figure, the frame is fixed at its lower ends and a static horizontal load is applied to its upper left corner. Members are subdivided into elements according to the numbers specified in the legends of the figures. As large deformations are not expected in the analyses, the total Lagrangian formulation (TLF) is used.

Figures 9 and 10 show the results of the elastic and elasto-plastic analyses under static loading. In the elastic analysis in which no plastic section is assumed to form within the elements, the ASI technique shows slow convergence and at least eight elements are needed for a member to obtain the converged solution. In the elasto-plastic analysis using the ASI technique, the collapse load obtained from the two-element model shows little difference from that of the converged solution since the numerical integration points are shifted to form plastic hinges at appropriate locations. However, it still shows slow convergence in the elastic range. As for the conventional method, convergence is extremely slow for both analyses. On the other hand, the ASI-Gauss technique shows that just two-element modeling is needed to obtain the converged solution both in elastic and elasto-plastic analyses.

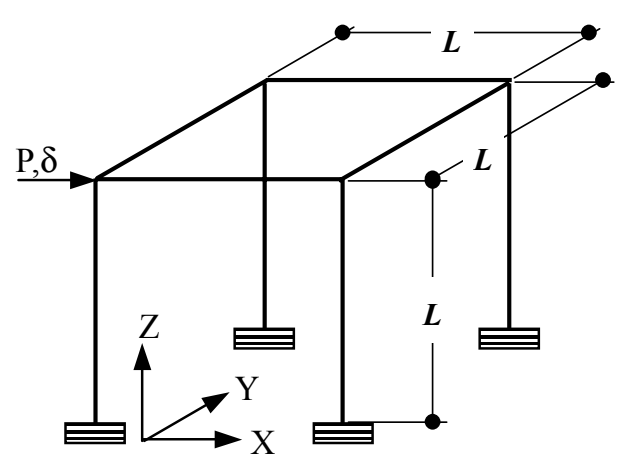

$$
\begin{aligned}
& \mathrm{L}=2.00 \mathrm{~m}, \mathrm{~A}=2.50 \times 10^{-3} \mathrm{~m}^{2} \\
& \mathrm{I}_{x}=\mathrm{I}_{\mathrm{y}}=5.21 \times 10^{-7} \mathrm{~m}^{4} \\
& \rho=7900 \mathrm{~kg} / \mathrm{m}^{3}, \mathrm{E}=206 \mathrm{GPa} \\
& v=0.3, \sigma_{y}=245 \mathrm{MPa} \\
& M_{x 0} \equiv \mathrm{M}_{\mathrm{y} 0}=7.66 \times 10^{3} \mathrm{Nm} \\
& \mathrm{N}_{0}=6.13 \times 10^{5} \mathrm{~N} \\
& M_{z 0}=1.12 \times 10^{5} \mathrm{Nm}
\end{aligned}
$$

Fig.8. Analyzed space frame 


\subsection{Elastic and Elasto-plastic responses of framed structures under dynamic loading}

In the analyses subjected under dynamic loading, the time increment $\Delta \mathrm{t}$ is set to $0.05 \mathrm{~ms}$ and the same model shown in Fig. 8 is used. A load of $8 \mathrm{kN}$ is applied in the elastic response analysis

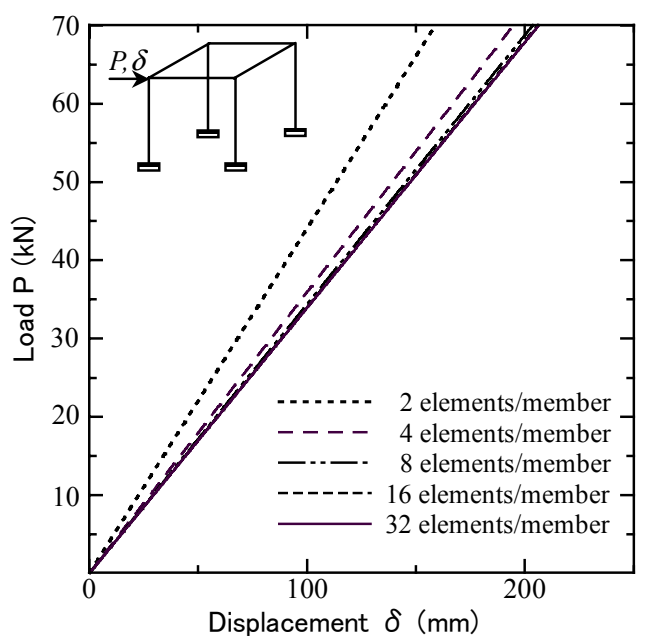

(a) Conventional method

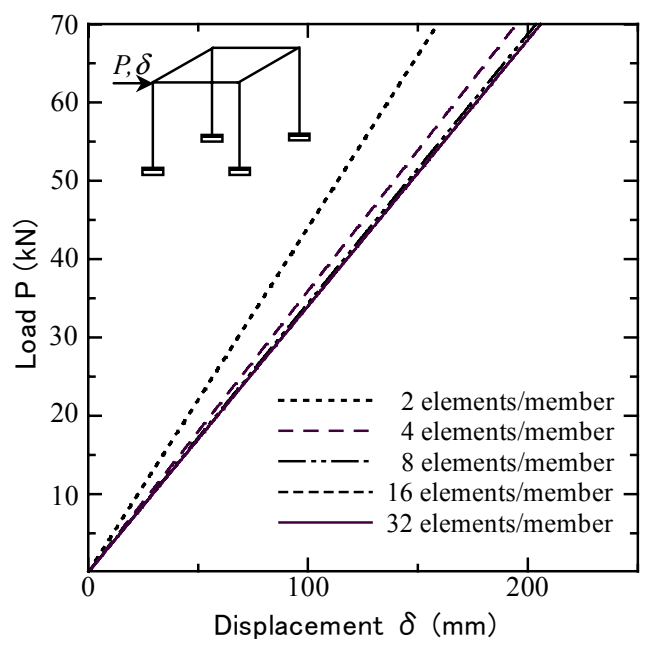

(b) ASI technique

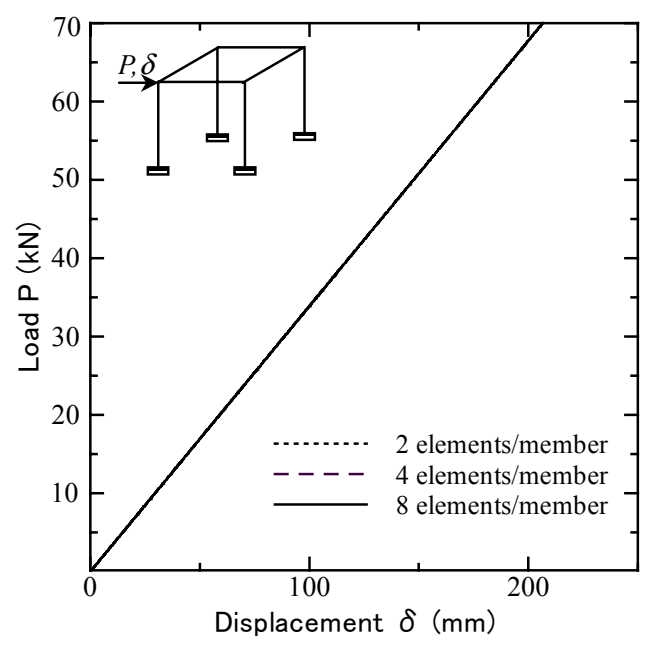

(c) ASI-Gauss technique

Fig.9. Load-displacement relations (elastic analysis)

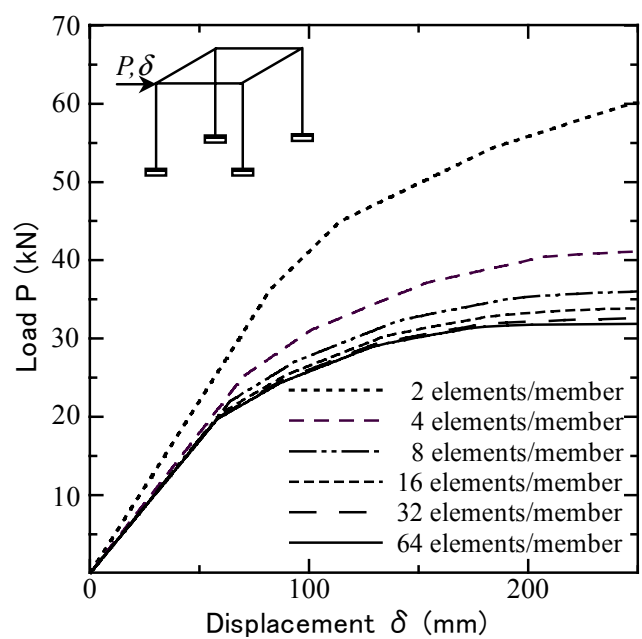

(a) Conventional method

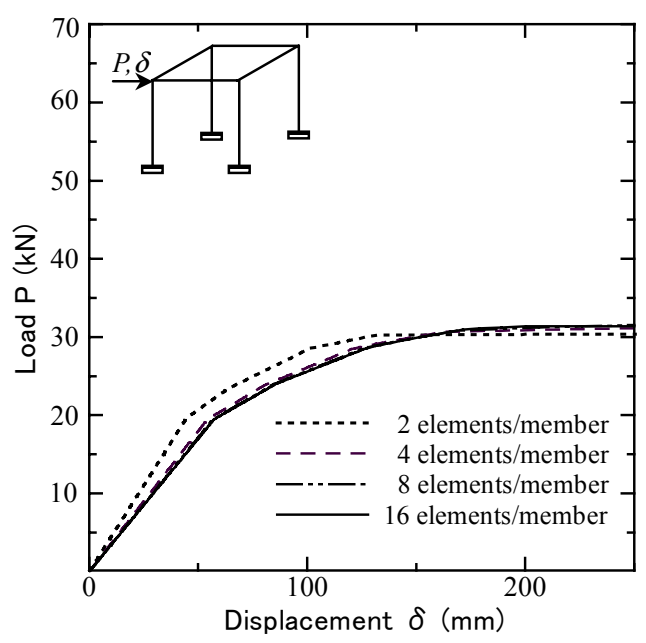

(b) ASI technique

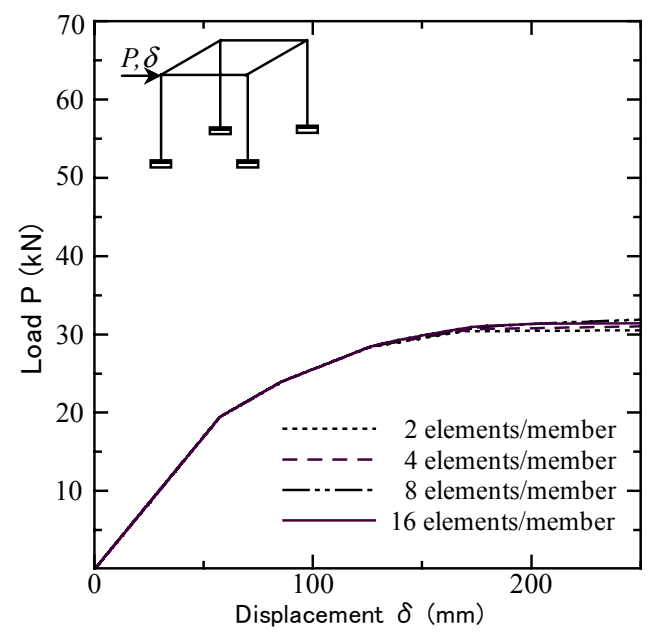

(c) ASI-Gauss technique

Fig.10. Load-displacement relations (elasto-plastic analysis) 
and $12 \mathrm{kN}$ in the elasto-plastic response analysis. Loading is done for a total of 100 steps $(5 \mathrm{~ms})$ in both analyses. $\beta=1 / 4$ is used for Newmark's $\beta$ method.

Figures 11 and 12 show the results of the elastic and elasto-plastic response analyses under dynamic loading. As in the analyses described in the previous section, the conventional method shows very slow convergence and sixteen-element modeling is necessary to obtain the converged solution in the elasto-plastic response analysis. The ASI technique gives comparatively better

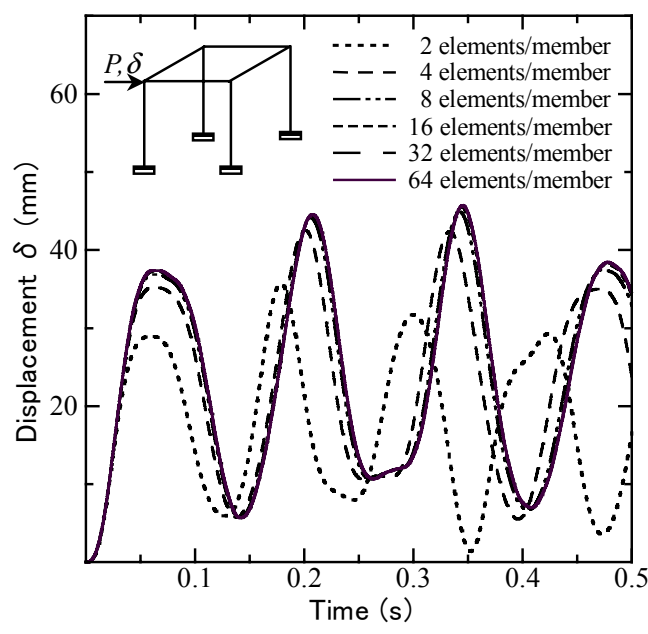

(a) Conventional method

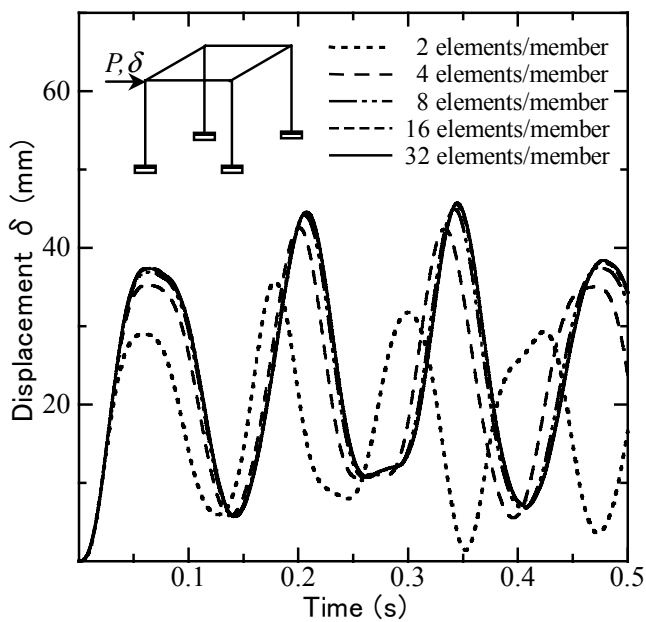

(b) ASI technique

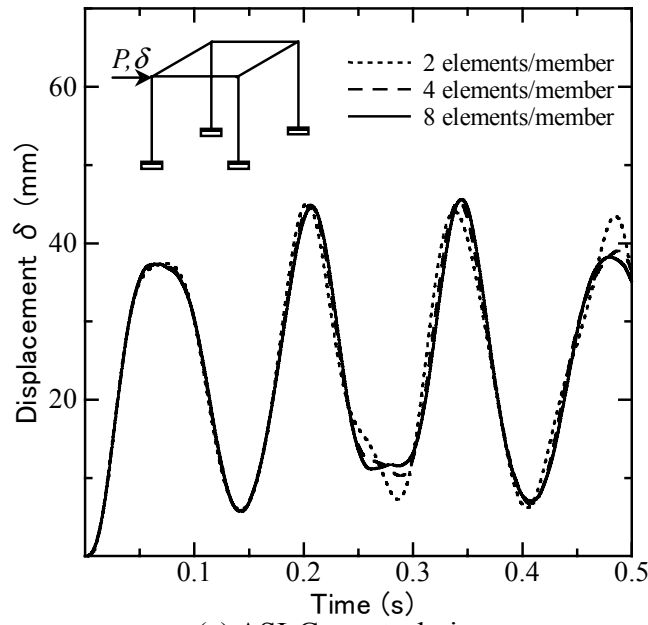

(c) ASI-Gauss technique

Fig.11. Elastic responses of a space frame

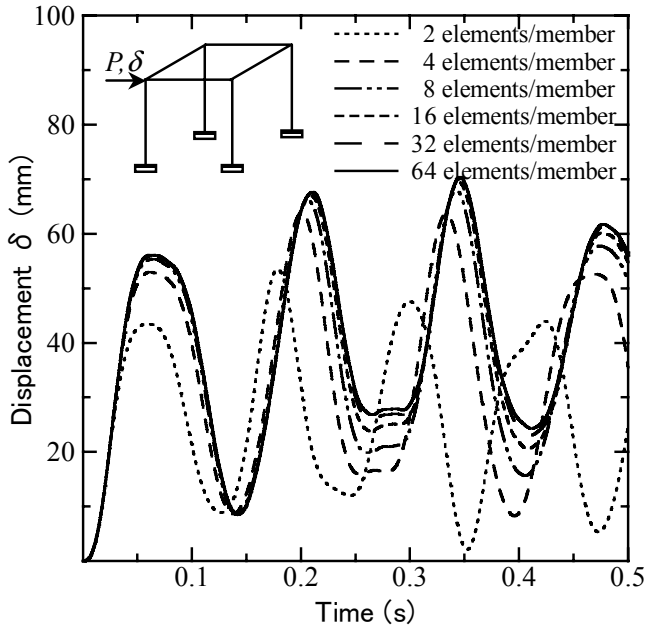

(a) Conventional method

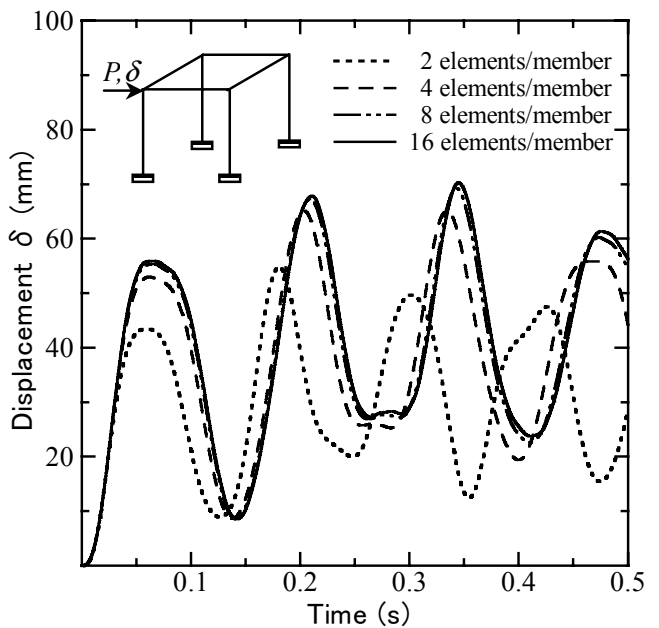

(b) ASI technique

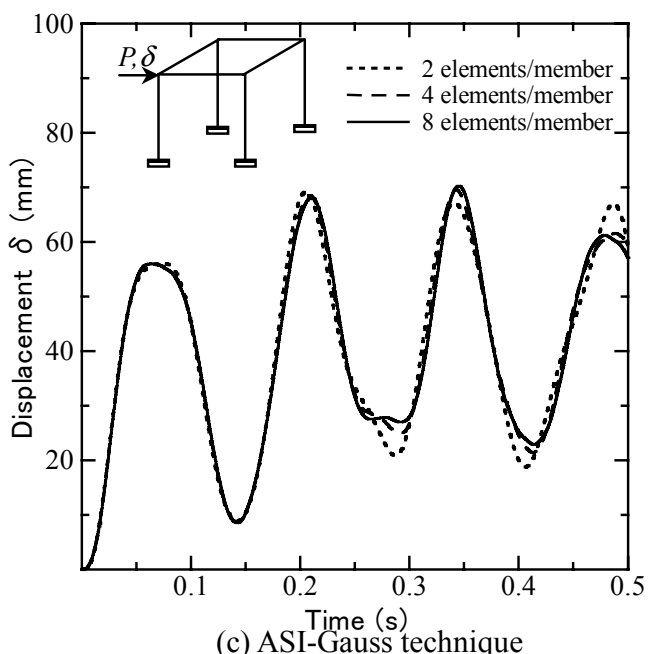

Fig.12. Elasto-plastic responses of a space frame 
results than the conventional method. However, when it comes to the model that uses only two elements per member, poor convergence is seen and the vibration mode is much different from that of the converged solution.

On the other hand, the ASI-Gauss technique shows very fast convergence in both analyses and nearly converged solutions are obtained even when the number of elements per member is two. From the above analyses, it is confirmed that the ASI-Gauss technique is an efficient method for analyses of frame structures both in elastic and elasto-plastic range, and even the two-element modeling is sufficient to acquire the results with high accuracy and reliability.

\subsection{Impact analysis using a simple two-beam model}

In this study, impact phenomenon of two beams is simulated to verify the creditability of the elemental contact algorithm. The analyzed model, its physical properties and material constants are shown in Fig.13. One of the beams is fixed at its both ends while the other one moves freely. Initial velocity of $50 \mathrm{~m} / \mathrm{s}$ is applied to the free beam. The beams are modeled with two elements per each member. The ASI-Gauss technique is applied, and the updated Lagrangian formulation (ULF) is used since large deformations are expected in the analysis. Damping effect is not considered in the analysis. Although using a value between $1 / 6$ and $1 / 4$ for $\beta$ in Newmark's $\beta$ method gives more accurate results, 0.4 is set for $\beta$ in order to stabilize the calculations [6]. The time increment $\Delta t$ is set to $10 \mu \mathrm{s}$. The calculation is done for a total of $3000 \mathrm{steps}(0.03 \mathrm{~s})$.

Figure 14 shows the sum of kinetic and potential energies, strain energy and the total of all

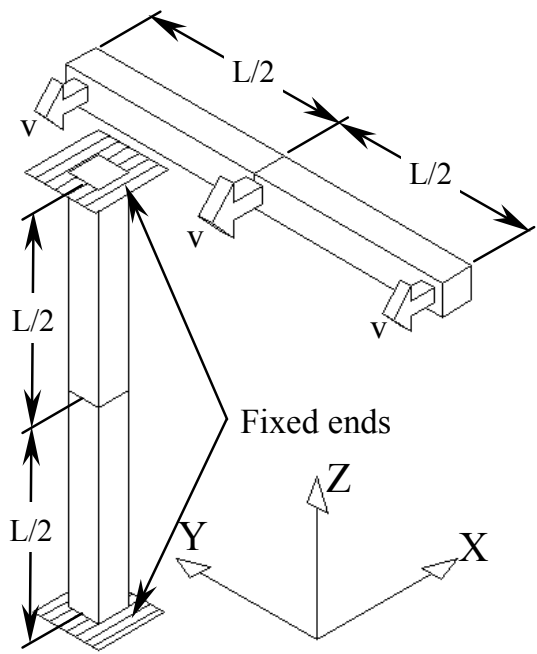

$$
\begin{aligned}
& \mathrm{L}=1.00 \mathrm{~m}, \mathrm{v}=50 \mathrm{~m} / \mathrm{s} \\
& \mathrm{A}=2.50 \times 10^{-3} \mathrm{~m}^{2} \\
& \mathrm{I}_{\mathrm{x}}=\mathrm{I}_{\mathrm{y}}=5.21 \times 10^{-7} \mathrm{~m}^{4} \\
& \rho=7900 \mathrm{~kg} / \mathrm{m}^{3}, \mathrm{E}=206 \mathrm{GPa} \\
& v=0.3, \sigma_{\mathrm{y}}=245 \mathrm{MPa} \\
& \mathrm{M}_{\mathrm{x} 0} \equiv \mathrm{M}_{\mathrm{y} 0}=7.66 \times 10^{3} \mathrm{Nm} \\
& \mathrm{N}_{0}=6.13 \times 10^{5} \mathrm{~N}, \mathrm{M}_{\mathrm{z} 0}=1.12 \times 10^{5} \mathrm{Nm}
\end{aligned}
$$

Fig.13. Analyzed two-beam model

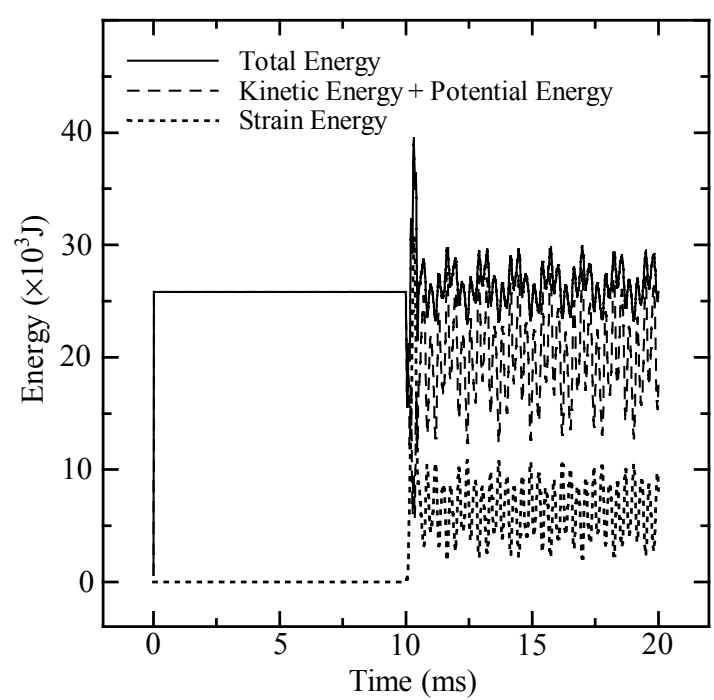

Fig.14. Kinetic, potential and strain energies in the two-beam model 
three for the whole model. Energies for both the colliding and the fixed beams constituted by a total of four elements are calculated by using the following equations:

$$
\begin{aligned}
\mathrm{KE} & =\frac{1}{2} \sum_{\mathrm{i}=1}^{4} \rho \mathrm{A} \frac{\mathrm{l}_{\mathrm{i}}}{2}\left(\mathrm{v}_{\mathrm{i} 1}{ }^{2}+\mathrm{v}_{\mathrm{i} 2}{ }^{2}\right) \\
\mathrm{PE} & =\sum_{\mathrm{i}=1}^{4} \rho \mathrm{A} \frac{1_{\mathrm{i}}}{2} \mathrm{~g}\left(\mathrm{~h}_{\mathrm{i} 1}+\mathrm{h}_{\mathrm{i} 2}\right) \\
\mathrm{SE} & \left.=\frac{1}{2} \sum_{\mathrm{i}=1}^{4}\left\{\sigma_{\mathrm{i}}\right\} \varepsilon_{\mathrm{i}}\right\} \mathrm{l}_{\mathrm{i}}
\end{aligned}
$$

Here, KE, PE and SE stand for kinetic energy, potential energy and strain energy, respectively. $\left\{\sigma_{\mathrm{i}}\right\},\left\{\varepsilon_{\mathrm{i}}\right\}, \mathrm{h}_{\mathrm{i}}, \mathrm{l}_{\mathrm{i}}$ represent the resultant force vector, the generalized strain vector, $\mathrm{z}$ coordinates and the length of the element $E_{i}(i=1,2,3,4)$. Subscripts 1 and 2 denote the nodal points of the corresponding element.

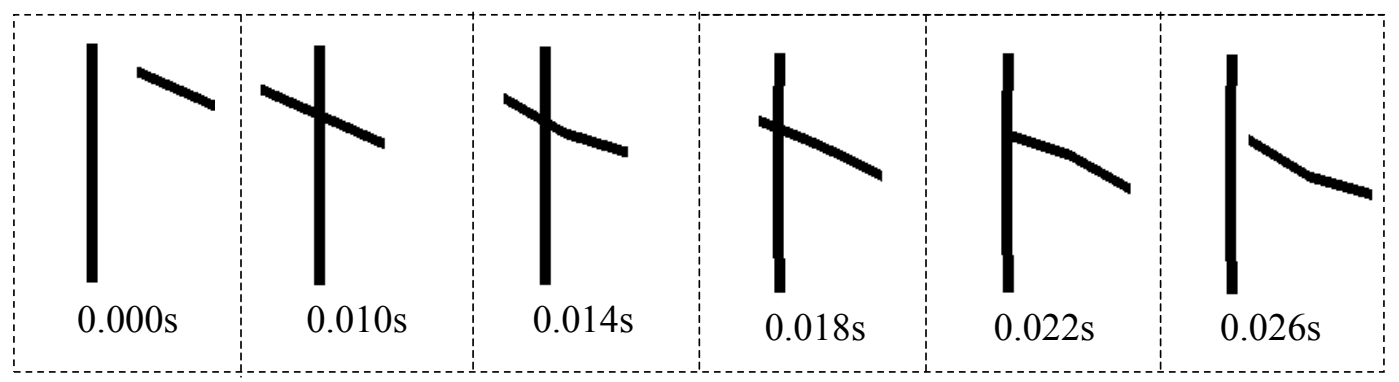

Fig.15. Collision analysis of a simple two-beam model

As seen from the figure, kinetic and potential energies occupy all of the total energy before the impact takes place. After the impact, both beams deflect and vibrate as seen in Fig.15. As a consequence, the strain energy is stored up in the beams and the sum of the other two decreases. However, the total energy remains almost unchanged although fluctuations are seen after the impact. The main reason for these fluctuations is considered to be the occurrence of longitudinal and bending waves. Nevertheless, the elemental contact algorithm used in this study is considered to be sufficiently reliable.

\section{Structural collapse analysis of framed structures under impact loads}

In this section, dynamic collapse analyses are performed using ASI-Gauss technique to simulate the impact of a small aircraft into a ten-storied steel framed structure. A total of four cases are analyzed using different values for three parameters: cruise speed, size and weight of the aircraft. Details of the analyzed model, propagation of impact loads, response of the structures and the extent of impact damage are discussed in this section.

\subsection{Outline of the analyzed model}

Figure 16 shows the analyzed ten-storied framed structure and the aircraft. Their dimensions, physical properties and material constants are also shown in the figure. It is assumed that the ten-storied framed structure is made of steel and the aircraft duralumin.

The weight of the floor system, which amounts to twenty times the own weight of the whole structure, is applied to the model in the form of an increase in the density $\rho$ of the beams. The ten-storied framed structure is fixed at its lower ends while none of the element is fixed in the aircraft model. It is assumed that the total weight of the aircraft is uniformly distributed in its elements. And this is implemented by increasing the density $\rho$ of all its elements. The aircraft has zero degree of inclination from the horizon and an initial velocity is applied to it. Both structures are modeled by using two elements per each member. The total number of elements is 1698 , and 


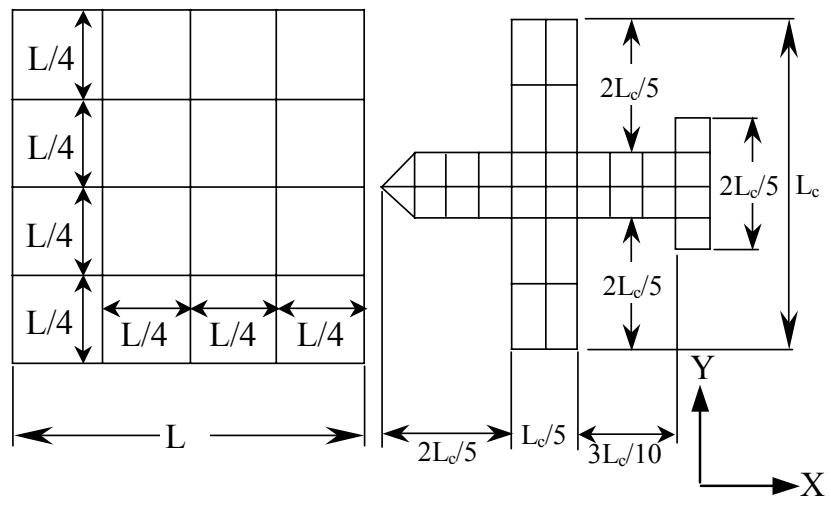

\begin{tabular}{|c|c|c|c|}
\hline & Body 1 & Body 2 & Unit \\
\hline $\mathrm{L}$ & 16 & - & $\mathrm{m}$ \\
\hline $\mathrm{L}_{\mathrm{c}}$ & - & 15 & $\mathrm{~m}$ \\
\hline $\mathrm{h}$ & 30 & - & $\mathrm{m}$ \\
\hline$h_{c}$ & - & 2 & $\mathrm{~m}$ \\
\hline$h_{a}$ & - & 21.50 & $\mathrm{~m}$ \\
\hline A & $2.19 \times 10^{-2}$ & $2.50 \times 10^{-3}$ & $\mathrm{~m}^{2}$ \\
\hline $\mathrm{I}_{\mathrm{x}}$ & $6.66 \times 10^{-4}$ & $5.21 \times 10^{-7}$ & $\mathrm{~m}^{4}$ \\
\hline $\mathrm{I}_{\mathrm{y}}$ & $2.24 \times 10^{-4}$ & $5.21 \times 10^{-7}$ & $\mathrm{~m}^{4}$ \\
\hline$\rho$ & 7900 & 2800 & $\mathrm{kgm}^{-3}$ \\
\hline $\mathrm{E}$ & 206 & 69 & Gpa \\
\hline$\sigma_{\mathrm{y}}$ & 240 & 195 & Mpa \\
\hline$v$ & 0.30 & 0.335 & \\
\hline $\mathrm{M}_{\mathrm{xo}}$ & $7.99 \times 10^{5}$ & $6.09 \times 10^{3}$ & $\mathrm{Nm}$ \\
\hline $\mathrm{M}_{\mathrm{yo}}$ & $2.69 \times 10^{5}$ & $6.09 \times 10^{3}$ & $\mathrm{Nm}$ \\
\hline $\mathrm{N}_{\mathrm{o}}$ & $5.25 \times 10^{6}$ & $4.88 \times 10^{5}$ & $\mathrm{~N}$ \\
\hline $\mathrm{M}_{\mathrm{zo}}$ & $1.12 \times 10^{5}$ & $1.12 \times 10^{5}$ & $\mathrm{Nm}$ \\
\hline
\end{tabular}

Body 1: ten-storied steel framed structure

Body 2: colliding body (made of duralumin)

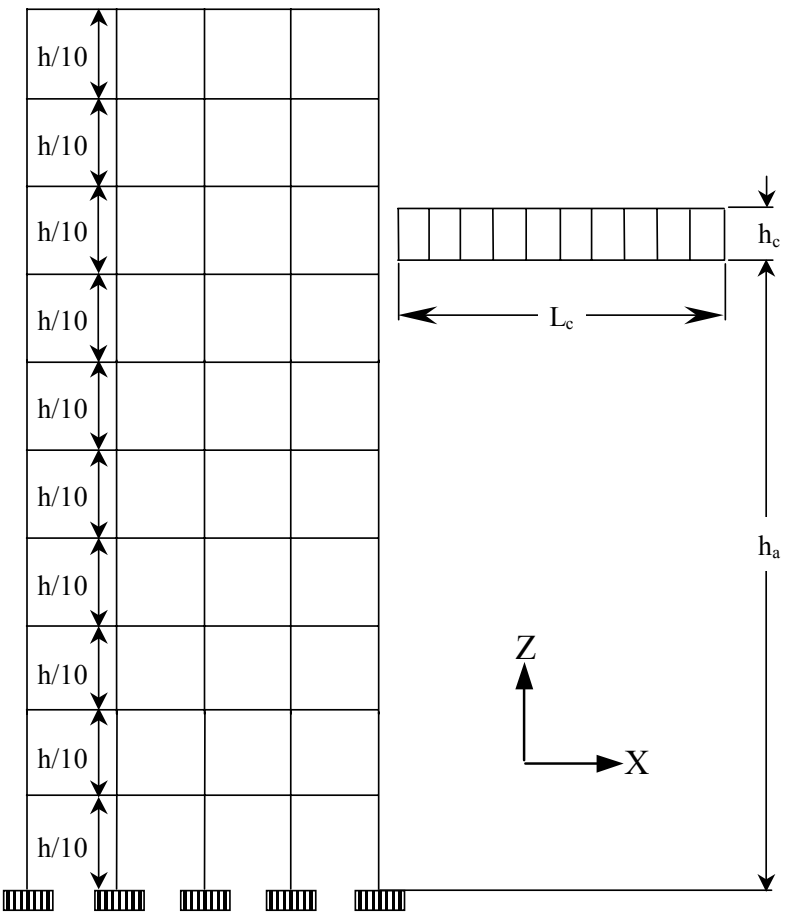

Fig.16. Analyzed ten-storied steel framed structure and colliding body

the total number of freedom is 7308 .

\subsection{Parameters set in the analyses}

A total of four analyses are performed using different values for cruise speed, size and weight of the aircraft. The combinations of these parameters are shown in Table 1.

Table 1 Parameters of the aircraft

\begin{tabular}{|c|c|c|c|}
\hline Analyzed cases & Cruise speed $[\mathrm{kmph}]$ & ${\text { Size } \mathrm{L}_{\mathrm{c}}[\mathrm{m}]}$ & Weight $[\mathrm{kg}]$ \\
\hline Case I & 440 & 15 & 15000 \\
\hline Case II & 320 & 15 & 15000 \\
\hline Case III & 440 & 15 & 12000 \\
\hline Case IV & 440 & 12 & 15000 \\
\hline
\end{tabular}

In all the four analyses, the ASI-Gauss technique with the linear Timoshenko beam element is used and member fracture and elemental contact are both considered. Damping effect is not considered in all analyses. The updated Lagrangian formulation (ULF) is used to be able to cope with large deformations of the elements. The Conjugate Gradient (CG) method is used as the solver 
to reduce the need for memory resources. $\beta=0.4$ is used for Newmark's $\beta$ method and the time increment $\Delta \mathrm{t}$ is set to $10 \mu \mathrm{s}$. The calculation is done for a total of $25000 \mathrm{steps}(0.25 \mathrm{~s})$ for each case. The calculation for each case takes approximately $9 \mathrm{CPU}$ hours with a personal computer $(2.4 \mathrm{GHz}$ CPU, 256MB RAM).

\subsection{Structural collapse analysis of the ten-storied framed structure under impact loads}

Figure 17 shows the results of the first analysis (Case I). A total of six colors are used to

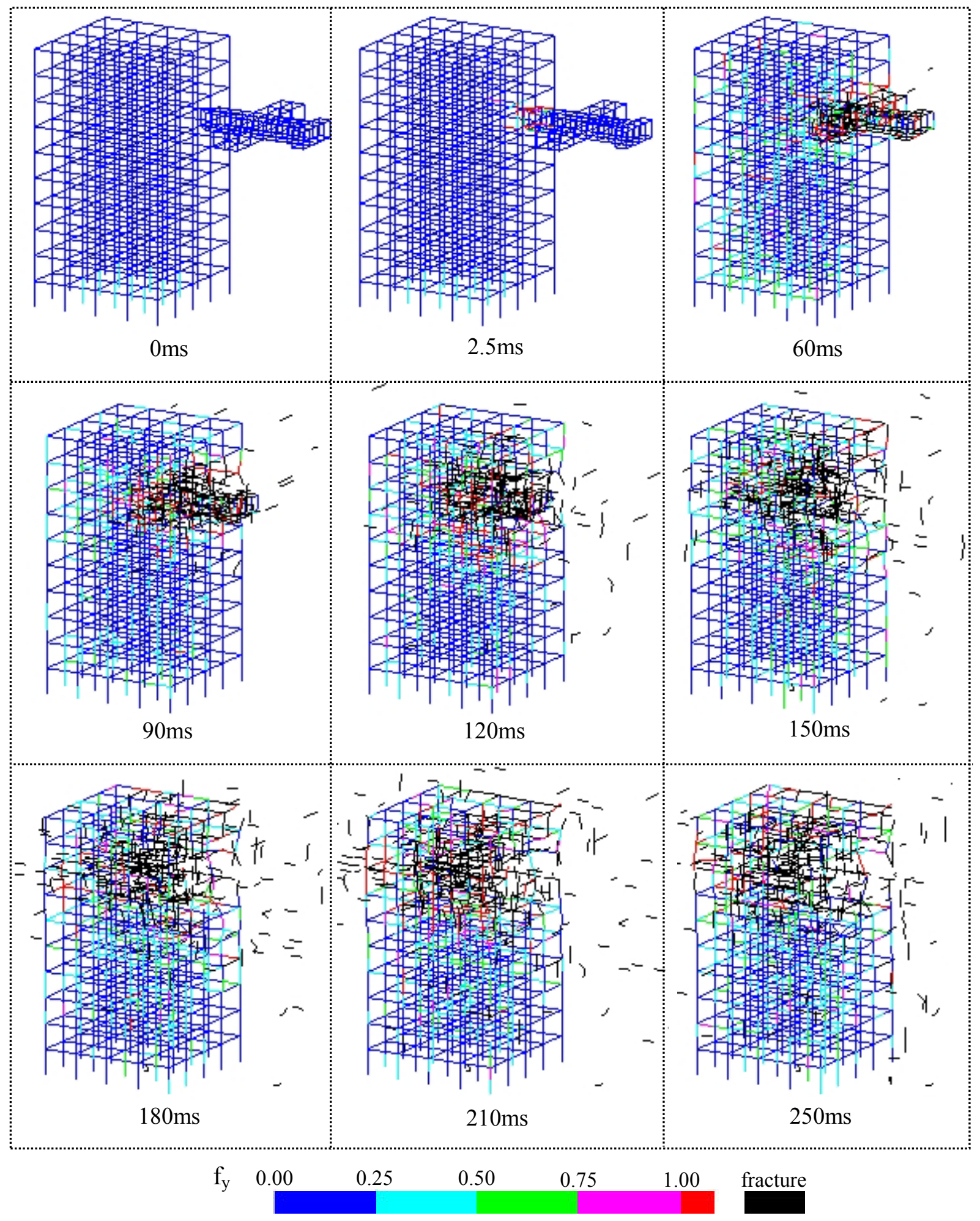

Fig.17. Impact analysis of a small aircraft against a ten-storied steel framed structure (Case I) 
demonstrate the tendency of the elements to yield or fracture. The numbers in the color palette indicate the values of $f_{y}$ in Eq.(14). Red color $\left(f_{y}=1.0\right)$ means a plastic hinge is formed within the element and black color is used for fractured elements.

Propagation of impact loads can be confirmed by observing the spread of colors in the figure. Immediately after the impact, red color propagates into the structures from the point of impact. And the elements near the area of impact turn to black, that is, they start to fracture. Moreover, it is seen that the colors travel down the columns and move backwards very fast. This phenomenon is seen mainly in the columns and considered as the propagation of shock waves. And red-colored elements are temporarily found even in the lowest floor, and this means that even the lowest floor is affected, to some extent, by the impact.

Figures 18(a) to 18(d) show the extent of damage to the steel framed structure for all four

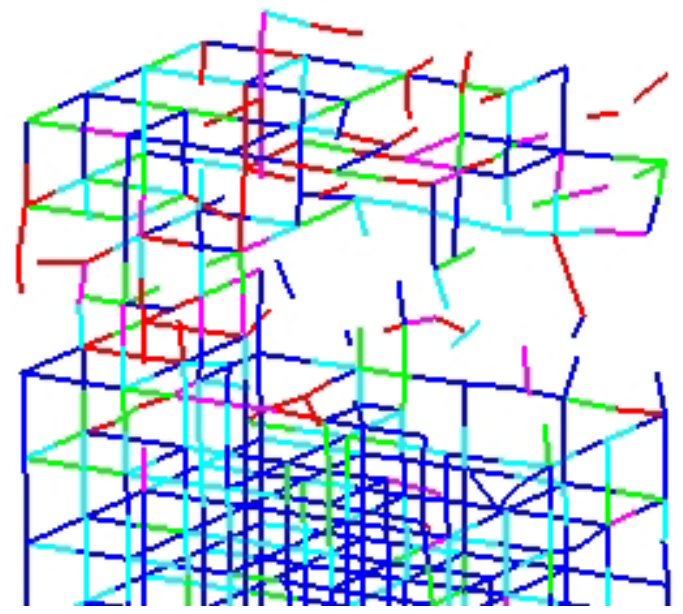

(a) Case I

Cruise speed $=440 \mathrm{kmph}, \mathrm{L}_{\mathrm{c}}=15 \mathrm{~m}$, Weight $=15000 \mathrm{~kg}$ Pre-impact kinetic energy $=112 \times 10^{6} \mathrm{~J}$ Number of fractured elements $=713$

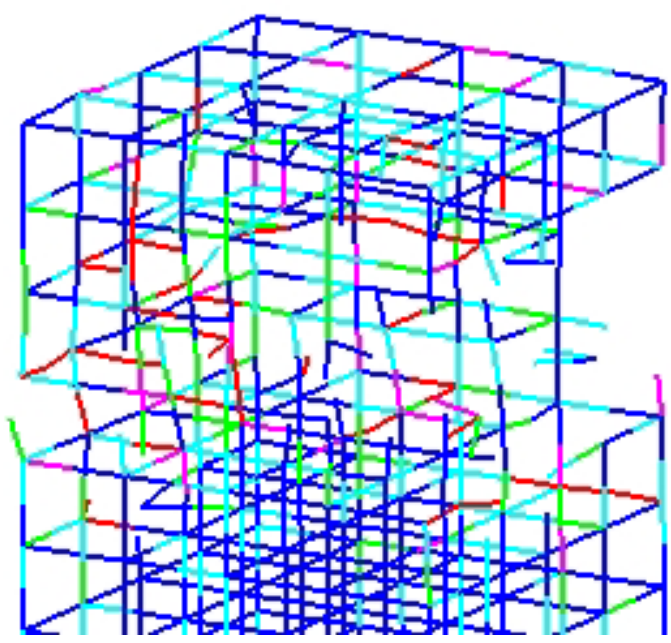

(c) Case III

Cruise speed $=440 \mathrm{kmph}, \mathrm{L}_{\mathrm{c}}=15 \mathrm{~m}$, Weight $=12000 \mathrm{~kg}$ Pre-impact kinetic energy $=90 \times 10^{6} \mathrm{~J}$ Number of fractured elements $=568$

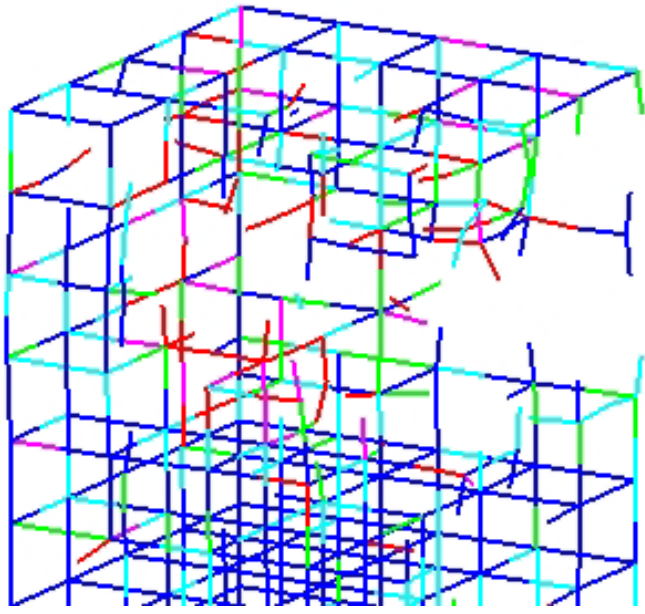

(b) Case II

Cruise speed $=320 \mathrm{kmph}, \mathrm{L}_{\mathrm{c}}=15 \mathrm{~m}$, Weight $=15000 \mathrm{~kg}$ Pre-impact kinetic energy $=59 \times 10^{6} \mathrm{~J}$ Number of fractured elements $=700$

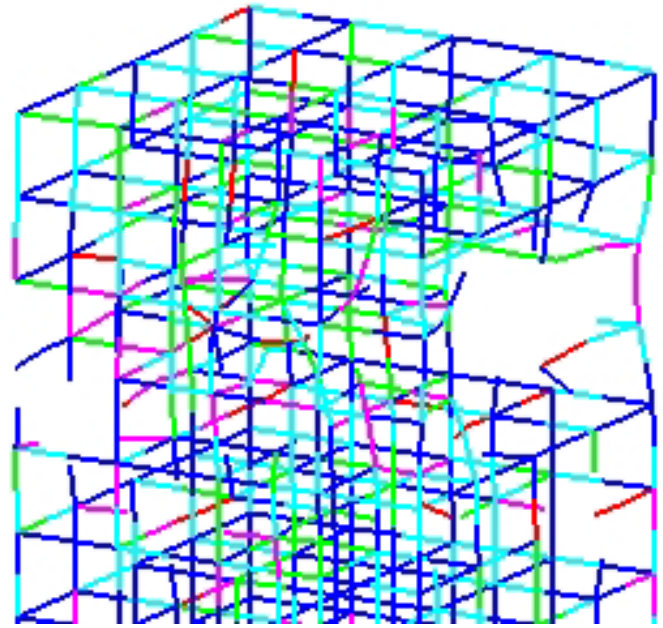

(d) Case IV

Cruise speed $=440 \mathrm{kmph}, \mathrm{L}_{\mathrm{c}}=12 \mathrm{~m}$, Weight $=15000 \mathrm{~kg}$ Pre-impact kinetic energy $=112 \times 10^{6} \mathrm{~J}$ Number of fractured elements $=521$

\section{$f_{y} 0.00$ \\ 0.25 \\ 0.50 \\ 0.75 \\ 1.00}

Fig.18. Impact damage to the ten-storied framed structure

(only the upper five floors are shown and fractured elements are excluded) 
cases. In order to show the damaged areas clearly, only the upper five floors are plotted and the fractured elements are excluded. If we focus on Case I, II and III, the largest damage is seen in Case I in which the damage extends to the sixth floor and most of the inner columns are cut off. Pre-impact kinetic energy is also the largest in Case I, and so it can be said that pre-impact kinetic energy of the aircraft is one of the factors that influence the impact damage. However, in spite of the smaller pre-impact kinetic energy, the impact damage in Case II is considerably larger that that in Case III. This indicates that the weight of the aircraft has a stronger influence than the velocity.

If we focus on Case I and IV, it is seen that less inner columns are cut off in Case IV although the kinetic energy of the aircraft is the same. This result can be interpreted in such a way that the size of the aircraft has a strong influence on the impact damage. However, it is seen that the smaller the aircraft, the larger the number of its members that pass through the ten-storied framed structure without collision. Therefore, further study is needed to clarify the influence of the size of the aircraft. Moreover, soon after impact, tensile stresses are observed in the columns that had been compressed by gravity loads before impact as shown in Fig.19. There is a possibility that these tensile stresses lead to some degree of structural damage especially in the joints of beams and columns. Therefore, detailed analyses are necessary to investigate this phenomenon.

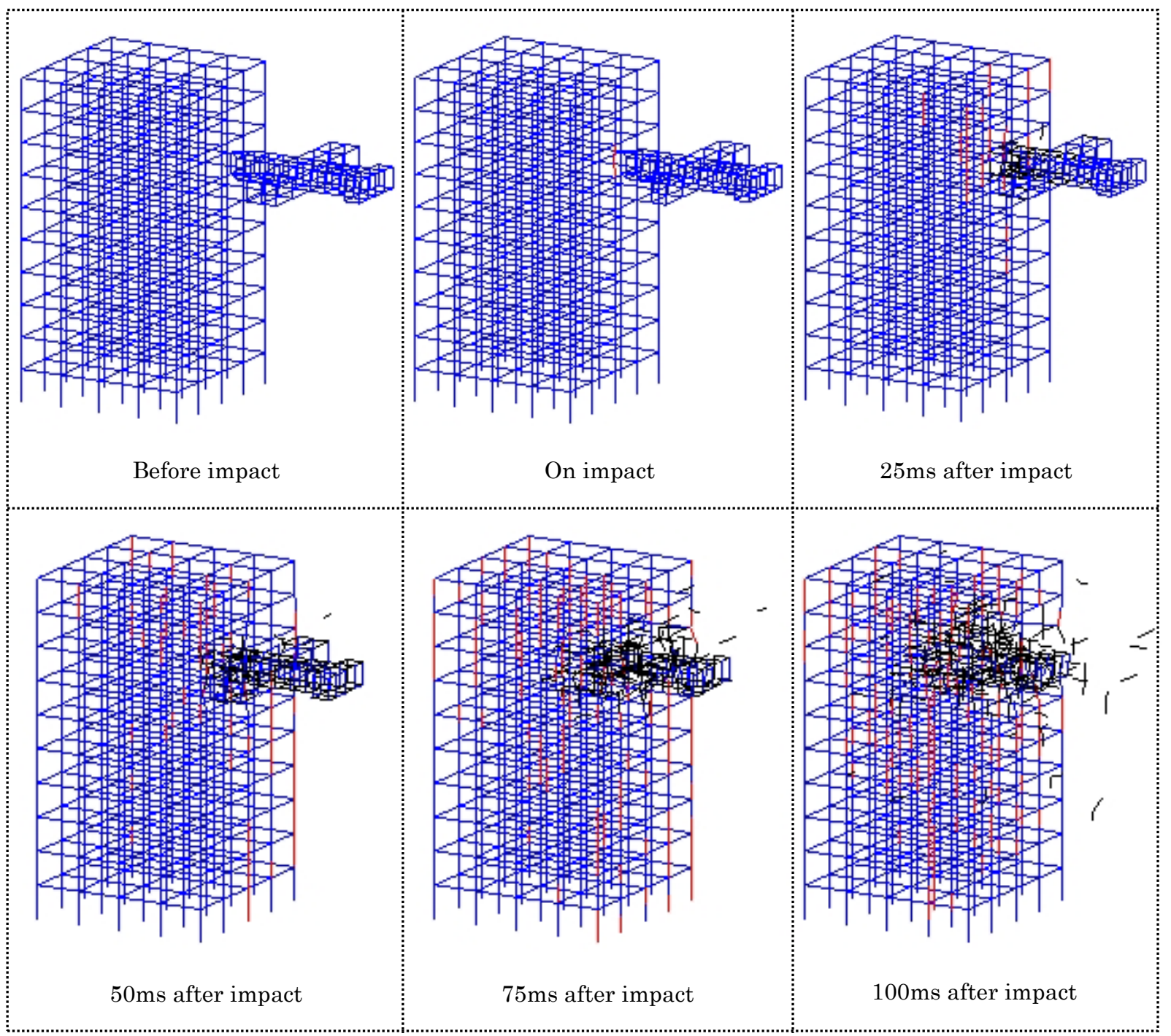

Elements in which tensile stresses are observed

Fractured elements

Fig.19. Tensile stresses observed in the ten-storied framed structure after impact (Case I) 


\section{Conclusion}

The formerly developed ASI technique for the linear Timoshenko beam element provides higher computational efficiency than the conventional finite element method, and is known to be able to cope with dynamic behaviors with strong nonlinearities including such phenomena as member fracture. However, it still lacked accuracy in elastic range when the number of elements per member is small. In this study, the ASI-Gauss technique, which deals elastic members by locating the stress evaluation points of two consecutive elements at Gaussian points, is proposed. Elasto-plastic analyses under both static and dynamic loading are performed to verify the proposed technique, and it is confirmed that nearly converged solutions are obtained even when the number of elements per member is two. It gives results with high accuracy at very low calculation cost, which may act efficiently in application to analyses of large-scale framed structures.

Instead of applying impact loads in the form of nodal forces, impact phenomenon is simulated by means of contacts between the elements involved. This elemental contact algorithm is also useful to simulate fractured elements colliding with other elements. The elemental contact algorithm is verified from the point of conservation of energy and the result showed its high reliability.

The ASI-Gauss technique with the elemental contact and the member fracture algorithms are applied to dynamic analyses with strong discontinuities, where impact of an aircraft against a ten-storied framed structure body is discussed using four different sets of parameters for the aircraft. From the results, we observed the propagation phenomenon of impact loads and shock waves. Also, a proper difference in impact damage is obtained by different sets of parameters, and in reasonably short calculation time. Therefore, the numerical analysis code used in this study is considered to be an efficient code for impact analyses of large-scale framed structures. However, further study is considered necessary to clarify the effect of the size of aircraft on the impact damage and to evaluate the structural damage caused by the tensile stresses of the columns.

\section{References}

[1] Cundall, P.A., A Computer Model for simulating Progressive, Large-scale Movement in Blocky Rock System, Proceedings of the International Symposium on Rock Mechanics, II-8, pp.129-136, 1971.

[2] Shi, G.H. and Goodman, R.E., Discontinuous Deformation Analysis, Proceedings of $25^{\text {th }}$ U.S. Symposium on Rock Mechanics, pp.269-277, 1984.

[3] Tagel-Din, H. and Meguro, K., Nonlinear Simulation of RC Structures Using Applied Element Method, Structural Engineering / Earthquake Engineering, Vol.17, No.2, pp.137-148, 2000.

[4] Toi, Y. and Isobe, D., Adaptively Shifted Integration Technique for Finite Element Collapse Analysis of Framed Structures, Int. J. Numer. Methods Eng., Vol.36, pp.2323-2339, 1993.

[5] Toi, Y. and Isobe, D., Finite Element Analysis of Quasi-static and Dynamic Collapse Behaviors of Framed Structures by the Adaptively Shifted Integration Technique, Computers and Structures, Vol.58, No.5, pp.947-955, 1996.

[6] Isobe, D. and Toi, Y., Analysis of Structurally Discontinuous Reinforced Concrete Building Frames Using the ASI Technique, Computers and Structures, Vol.76, No.4, pp.471-481, 2000.

[7] Isobe, D. and Morishita, M., Debris Impact Analysis of Large-Scale Space Structures by Using ASI-FEM, Transactions of the Japan Society of Mechanical Engineers, Part A, Vol.64, No.627, pp.2726-2733, 1998, in Japanese.

[8] Isobe, D. and Tsuda, M., Development of Seismic Collapse Analysis Code for RC Framed Structures Using Finite Element Method, Journal of Structural Engineering, Vol.48B, pp.385-394, 2002, in Japanese.

[9] Press, W. H., Flannery, B. P., Teukolsky, S. A. and Vetterling, W. T., Numerical Recipes in FORTRAN: The Art of Scientific Computing, 2nd ed., Cambridge University Press, pp. 140-155, 1992. 